\title{
In Vitro Antioxidant Property and Phytochemical Constituents of Senna alata Leaves Aqueous Extract Collected in Ngaoundéré (Cameroon)
}

\author{
Jeweldai Vedekoi ${ }^{\star}$, Sokeng Dongmo Selestin \\ ${ }^{1}$ Department of Biological Sciences, Faculty of Science, University of Ngaoundéré, PO Box 454 Ngaoundéré, Cameroon
}

Article Information

Received 1 January 2020

Received in revised form 7 June 2020

Accepted 09 June 2020

Keywords:

Senna alata,

total polyphenols,

total flavonoids,

FRAP,

$\mathrm{DPPH}$

Corresponding Author:

E-mail : jeweldai2014@yahoo.fr

Mob.: +237690677322

DOI: 10.20510/ukjpb/8/i3/1592309659

\begin{abstract}
Leaves extract of Senna alata L. is a plant used as indigenous medicine to treat various types of disease like ulcers, stomach, pain and fever. The present study was undertaken to study the phytochemical screening, total phenolic compounds (TPC), total flavonoid compounds (TFC) and in vitro antioxidant of Senna alata leaves' extract growing in Ngaoundéré town (Cameroon). Respective bioactivities of the phytochemicals were determined. Quantitative analysis of the total phenolic content was determined by using the Folin-Ciocalteu method while total flavonoid was estimated using aluminium trichloride $\left(\mathrm{AICl}_{3}\right)$. The antioxidant capacities in the forms of DPPH (2,2-diphenyl-1-picrylhydrazyl) and FRAP (Ferric Reducing Antioxidant Power) were evaluated by spectrophotometric methods. For these purposes, aqueous extract were prepared. Now the experimental screening of phytochemicals showed negative results for the absence of reducing compounds, steroids/triterpenes, and tannins. The results showed that TPC, TFC values were higher: $14.768 \pm 0.26 \mathrm{mg}$ GAE per $\mathrm{g}$ of extract, $4.32 \pm 0.12 \mathrm{mg}$ Ru per $\mathrm{g}$ of extract, respectively. The Senna alata Leaves' extract (SALE) exhibited the best DPPH inhibition concentration $50 \%$ $\left(\mathrm{IC}_{50}=12.05 \mathrm{mg} \cdot \mathrm{mL}^{-1}\right)$, and FRAP method $\left(\mathrm{IC}_{50}=2.79 \mathrm{mg} \cdot \mathrm{mL}^{-1}\right)$ compared to that of the positive control, ascorbic acid $\left(\mathrm{IC}_{50}=17.69 \mathrm{mg} / \mathrm{mL}\right)$; Hence, extract from the leaves of Senna alata contains high secondary metabolites which accounts for its strong antioxidant ability thus justifying its use as natural occurring antioxidants in folkloric medicine.
\end{abstract}

\section{Introduction}

Oxygen is a highly reactive atom that is capable of becoming part of potentially damaging molecules commonly called "free radicals." Living organisms are equipped with a defense system to neutralize free radicals such as superoxide anion radicals $\left(\mathrm{O}_{2^{-}}\right)$, hydroxyl radicals $(\mathrm{HO} \cdot)$, and non-free-radical species, such as hydrogen peroxide $\left(\mathrm{H}_{2} \mathrm{O}_{2}\right)$ and singlet oxygen $\left({ }^{1} \mathrm{O}_{2}\right)^{1}$. If the production of free radicals exceeds the antioxidant capacity of a living system, free radicals are capable of attacking the healthy cells of the body to cause oxidative stress leading to the pathogenesis of several human's degenerative diseases like cancer, inflammation, atherosclerosis, neurological disease, cardiovascular disease and rheumatoid arthritis ${ }^{2}$.

During oxidative stress, free radicals not detoxified by the antioxidant system cause damage to biological molecules contained in cells, including the oxidation of DNA, proteins, lipids, and carbohydrates, but also secondary lesions due to the cytotoxic and mutagenic nature of the released metabolites lipid oxidation $^{3}$. Antioxidants are natural or chemical products which are defined as chemicals which, more specifically, delay the deterioration or discoloration caused by the oxidation and neutralization of free radicals but can also have toxicological effects and suspected carcinogenic potential ${ }^{5}$. In the search for alternatives antioxidant sources, the present research is focused on leaves of Senna alata.

S. alata L., (Synonym Cassia alata (L.) Roxb.,) belonging to the Leguminosae family and Fabaceae subfamily, is a herbaceous plant with thick downy branches, which is distributed in the many tropical countries including Cameroon. S. alata, commonly named ringworm cassia as the plant leaves were used for 
treatment of ringworm. It is recognizable by its dense and bright orange yellow flowers that are arranged spirally on its rachides, san average height of between 1 and 5 meters and has horizontally spread branches. The inflorescence looks like a yellow candle. It is often cultivated for medicinal purposes, and also as a pantropical ornamental shrub to warm temperate areas. The fruit is a pod, while the seeds are small and square in shape. The plant has been shown several pharmacological virtues. Its leaves are used against yellow fever or malaria, and as antiasthmatics, or antidiabetics ${ }^{6}$. The leaves are also specific for the treatment of ringworm and eczema ${ }^{7}$ (Co, 1989), scabies, athlete's foot ${ }^{8}$, herpes ${ }^{9}$ and insect bites ${ }^{10}$. Various extracts and different parts of $S$. alata have been reported to own many pharmacological activities such as laxative ${ }^{11}$, wound healing ${ }^{12}$, hypoglycaemic ${ }^{13}$, anti-bacterial ${ }^{14}$, analgesic ${ }^{15}$ and antiinflammatory ${ }^{16}$.

In this work, the present study was designed to determine the qualitative screening of phytochemicals, the total phenolic compounds (TPC), total flavonoid compounds (TFC) and to examine the in vitro antioxidant of $S$. alata leaves extract to ascertain its acclaimed use as natural occurring antioxidants in folkloric medicine.

\section{Materials and methods}

\subsection{Chemicals and reagents}

Ethanol, Folin-Ciocalteu reagent, anhydrous sodium carbonate $\left(\mathrm{Na}_{2} \mathrm{CO}_{3}\right)$, gallic acid, aluminum chloride $\left(\mathrm{AlCl}_{3}\right)$, crystalline sodium acetate, 2,2-Diphenyl-1-Picrylhydrazyl (DPPH), potassium ferricyanide, trichloroacetic acid (TCA), ferric chloride, Butylated Hydroxy Toluene (BHT), ascorbic acid were obtained from Sigma-Aldrich Chemicals (Yaoundé, Cameroun). All solvents and reagents used for the investigation were of analytical grade.

\subsection{Collection of plant material}

The freshly collected aerial part of the $S$. alata was gathered in September, 2019 from local area of Ngaoundéré town, Adamaoua Region of Cameroon. The sample was collected from its natural habitat. The plant was subsequently identified by Professor Pierre-Marie Mapongmetsem, a botanist in the Biological Sciences, Faculty of Science, University of Ngaoundéré, Cameroon. The voucher specimen was deposited under the reference number at the Cameroon National Herbarium at Yaoundé, Cameroun.

\subsection{Preparation of plant extract}

The S. alata leaves were prepared according to traditional use. Briefly, the freshly collected leaves part of the plant was cleaned and washed properly with tap water under running water, and dried in the shade at room temperature $\left(22-25^{\circ} \mathrm{C}\right)$ until constant weight for two weeks. Then, the dried plant materials was ground to a fine powder into a coarse with the help of a suitable grinder and passed through a 22 mesh sieve. The dry powder of the sample $(10 \mathrm{~g})$ was decocted with $100 \mathrm{~mL}$ of distiller water (1: 10) for 20 minutes and cooled. After decantation, the supernatant was filtered through a Whatman filter paper No. 1, concentrated at $55{ }^{\circ} \mathrm{C}$ by evaporating in a vacuum rotary evaporator $\left(\mathrm{HEILDOLPH}^{\circledR}\right)$ and dried to a constant weight in an oven set at $40{ }^{\circ} \mathrm{C}$. The dried extract was stored in at room temperature in a dry place prior to use refrigerator.

\subsection{Ethics statement}

For the collection of plant, no specific permits were required for the described field studies. For any locations/activities, no specific permissions were required. The location where the plant was collected was not privately-owned or protected in any way and the field studies did not involve endangered or protected species. This study was approved by the University of Cameroon's institutional review board.

\subsection{Qualitative phytochemical screening}

Preliminary qualitative phytochemical screening for the determination of secondary metabolites was carried out according to standard methods ${ }^{17-19}$ to detect the presence or absence of bioactive compounds.

\subsubsection{Test for flavonoids}

In a test tube, introduce $1 \mathrm{~mL}$ of extract to be tested, add $1 \mathrm{~mL}$ of hydrochloric acid $(\mathrm{HCl})$ and 3 magnesium shavings. The appearance of a red or yellow coloration reveals the presence of flavonoids.

\subsubsection{Test for tannins}

To $1 \mathrm{~mL}$ of extract to be analyzed, add $0.5 \mathrm{~mL}$ of a $1 \%$ aqueous solution of $\mathrm{FeCl}_{3}$. The presence of tannins is indicated by a greenish or blue-blackish coloration.

\subsubsection{Test for Coumarins}

Put $5 \mathrm{~mL}$ of extract in a tube, add $0.5 \mathrm{~mL}$ of $10 \% \mathrm{NH} 4 \mathrm{OH}$, mix and observe under UV at $366 \mathrm{~nm}$. Intense fluorescence indicates the presence of coumarins.

\subsubsection{Test for Alkaloids}

The tests are carried out by precipitation reactions with the reagents of Mayer and Wagner.

$1 \mathrm{~mL}$ of each extract is divided into two equal volumes. One volume is treated with $0.5 \mathrm{~mL}$ of

Mayer's reagent, the other with $0.5 \mathrm{~mL}$ of Wagner's reagent. The appearance of a white or brown precipitate, respectively, reveals the presence of the alkaloids.

\subsubsection{Test for Terpenoides/ steroids}

$5 \mathrm{~mL}$ of extract is added to $2 \mathrm{~mL}$ of chloroform and $3 \mathrm{~mL}$ of concentrated sulfuric acid. The formation of two phases and a brown color at the interphase of two liquids and a purple Pharm \& Biosci J. 2020: 8(3); 16 
coloration of the supernatant layer reveal the presence of terpenoids and sterols.

\subsubsection{Test for saponins: Foam test}

In a test tube, introduce $10 \mathrm{~mL}$ of extract to be tested and stirred for a few seconds then left to stand for $15 \mathrm{~min}$. A height of persistent foam indicates the presence saponins.

\subsubsection{Test for reducing compounds}

Put $1 \mathrm{~mL}$ of extract in a test tube, add $2 \mathrm{~mL}$ of Fehling's liquor (1 $\mathrm{mL}$ reagent $A$ and $1 \mathrm{~mL}$ reagent $B$ ), and incubate the whole for 8 $\min$ in a boiling water bath. The appearance of a brick-red precipitate indicates the presence of the reducing compounds.

\subsection{Total phenolics content determination}

For the determination of phenolic compounds present by FolinCiocalteu reagent, the method described by Singleton and Rossi $^{20}$ was used. This method provided the total phenolic content of a given sample. Briefly speaking, $0.1 \mathrm{~mL}$ (in the concentration of $1 \mathrm{mg} / \mathrm{ml}$ ) of plant extract solution was prepared in methanol and $0.5 \mathrm{~mL}$ of sample was introduced into test tubes. After this, $2.5 \mathrm{~mL}$ of $10 \%(\mathrm{v} / \mathrm{v})$ Folin- Ciocalteu reagent and $2 \mathrm{~mL}$ of $20 \% \mathrm{Na}_{2} \mathrm{CO}_{3}$ solution was added to the mixture and well shaken for 15 seconds. A set of gallic acid standard solutions (10, $20,40,60,80$ and $100 \mu \mathrm{g} / \mathrm{mL}$ ) were prepared as earlier in methanol. The tubes were covered with parafilm and incubated for 30 minutes at room temperature in the dark and the absorbance of the reaction mixtures was determined by UV-2100 SPECTROPHOTOMETER (UNICO ${ }^{\circledR}$ ) at $765 \mathrm{~nm}$. TPC was estimated from a standard curve of gallic acid $\left(0.2-1 \mathrm{mg}^{-\mathrm{mL}^{-1}}\right)$. All measurements were repeated three times and results were expressed as $\mathrm{mg}$ gallic acid equivalent (GAE) per grams of extract.

\subsection{Flavonoid content determination}

Colorimetric assay was used to determine the content of flavonoid according to known procedure ${ }^{21}$. For the reaction, $1 \mathrm{~mL}$ of the plant extract at the concentration of $1 \mathrm{mg} / \mathrm{mL}$ was added with $0.3 \mathrm{~mL}$ of $10 \%$ aluminum solution dissolved in methanol and the mixture was incubated for 15 minutes at room temperature. A set of standard solutions of Rutin $(20,40,60,80$ and $100 \mu \mathrm{g} /$ $\mathrm{mL}$ ) were prepared as mentioned earlier. The absorbance was measured for test and standard solutions using reagent blank at $510 \mathrm{~nm}$ using the UV-2100 SPECTROPHOTOMETER $\left(\mathrm{UNICO}{ }^{\circledR}\right)$. The total content of flavonoid was denoted as $\mathrm{mg}$ of $\mathrm{RU} / \mathrm{g}$ of extract.

\subsection{DPPH radical scavenging activity assay}

Radical-scavenging activity was determined by bleaching a purple solution of 1,1-diphenyl-2-picrylhydrazyl (DPPH) radical, followed by the change from a violet (DPPH॰) to a yellow $(\mathrm{DPPH}-$ $\mathrm{H})$ color, using a method developed by Blois ${ }^{22}$. DPPH stable free radical method is an easy, rapid and sensitive way to survey the antioxidant activity of a specific compound or plant extracts ${ }^{23}$. Herein, $3 \mathrm{ml}$ of crude extract solution in extract at different concentrations $(0,50,100,150$ and $200 \mu \mathrm{g} / \mathrm{mL})$ was pippeted and put into the microplate and then mixed with $1 \mathrm{~mL} \mathrm{DPPH}$ at a concentration of $0.1 \mathrm{mM}$ dissolved in methanol. The reaction mixture were shaken vigorously and incubated for $15 \mathrm{~min}$ in the darkness place at room temperature. Then, the absorbance of resulting solution was measured at $517 \mathrm{~nm}$ with a microplate reader. The inhibition of DPPH radical was calculated by comparing the results of the test (with extract) to those of the control (without extract) using the following formula as follows ${ }^{24}$ : $\%$ Inhibition $=\left[\left(A_{0}-A_{1}\right) / A_{0}\right] \times 100$, where: $A_{0}$ was the absorbance for the reference sample (just DPPH solution) and $A_{1}$ was the absorbance for the tested sample. The result was expressed as IC50 value (the concentration which corresponded to $50 \%$ of the initial DPPH concentration) obtained from the separate linear regression plots of the mean percentage of the antioxidant activity against concentration of the test extract $\left(\mathrm{mg} \cdot \mathrm{mL}^{-1}\right)$. All the run were triplicate.

\subsection{Ferric reducing antioxidant power (FRAP) activity}

The Ferric reducing antioxidant power procedure was followed to a modified method described by Bougandoura and Bendimerad ${ }^{25}$ with minor modifications as detailed in the following. The principle of this method is based on the reduction of the ferric-tripyridyl triazine complex to its ferrous colored form in the presence of antioxidants. Briefly, the aqueous extract was taken in various concentrations (50 to $1000 \mu \mathrm{g}$ per $\mathrm{mL}$ ) from the stock solution and was mixed with $2 \mathrm{~mL}$ of sodium phosphate buffer $(0.2 \mathrm{M}, \mathrm{pH}$ 6.6) and $2 \mathrm{~mL}$ of aqueous potassium ferricyanide (1\%) in a test tube. After incubation in water bath at $50^{\circ} \mathrm{C}$ for $20 \mathrm{~min}, 2 \mathrm{~mL}$ of $10 \%$ trichloroacetic acid was added to the mixture to stop the reaction, and the mixture was centrifuged at $3000 \mathrm{rpm}$ for $10 \mathrm{~min}$. The upper layer of the solution $(2 \mathrm{~mL})$ was mixed with $2 \mathrm{~mL}$ distilled water and $0.5 \mathrm{~mL}$ of $1 \%$ ferric chloride $\left(\mathrm{FeCl}_{3}\right)$ was prepared freshly in some distilled water and then the absorbance of reaction mixture was measured at $700 \mathrm{~nm}$ using the UV-2100 SPECTROPHOTOMETER (UNICO $\left.{ }^{\circledR}\right)$. Higher absorbance of the reaction mixture indicates an important reducing power. As positive control, ascorbic acid was used and results of antioxidant activity were expressed as absorbance reading. The iron (III) reducing activity determination was determined in triplicate and expressed in $\mathrm{mg}$ Ascorbic Acid Equivalent per $\mathrm{mL}$ of extract.

\subsection{Statistical analysis}

Data were reported as mean \pm standard deviation from three repetitions, except for IC50 values computed from linear regression of triplicates of each concentration tested. One-Way analysis of variance (ANOVA) followed by Dunnett's post hoc using SPSS version 16.0 were carried out to determine statistical significance between the means and $p$-values $<0.05$ were considered statistically significant. 


\section{Results and discussion}

\subsection{Phytochemical Screening}

One of the essential goals of a phytochemical test is the detection of the different families of secondary metabolites existing in the studied part of the plant by qualitative characterization reactions. The result of phytochemical test is summarized in Table 1. It appears from this table that the tests for alkaloids, phenolic compounds, saponins, and flavonoids were positive. In contrast, the tannins, steroids / terpenoids, and Reducing compounds were not detected. This result is contrary to a team of researchers who indicated the presence of alkaloids, phenols, tannins, flavonoids, saponins, steroids and sugar in the aqueous extract of the leaves of $\mathrm{S}$. alata ${ }^{26}$. The qualitative chemicals are an indication of an antioxidant and anti-inflammatory values of this plant and may be responsible for the traditional uses of $S$. alata leaves.

Table 1: Phytochemical screening of aqueous extract of Senna alata

\begin{tabular}{lc}
\hline Phytochemicals & Presence/absence \\
\hline Alkaloids & + \\
Phenolic compounds & + \\
Flavonoids & + \\
Tannins & - \\
Saponins & + \\
Triterpenes or steroids & - \\
reducing compounds & -
\end{tabular}

Presence of phytochemical is denoted by $(+)$ sign and absent of phytochemical is (-)

\subsection{Determination of total phenolic contents}

The presence of phenolic compounds identified in the leaves extract of $S$. alata in the current study could be responsible for its folkloric therapeutic usage for animals. The total phenolic content in the aqueous extract was $14.768 \pm 0.26 \mathrm{mg} / \mathrm{gram}$ GAE. Calibration curve from gallic acid showed maximum absorbance at $765 \mathrm{~nm}$ wavelength (equation $\mathrm{y}=3.8747 \mathrm{x}+0.0418, \mathrm{R}^{2}=$ $0.9815)$. These results are inferior to other studies which have presented a phenol content of $59.21 \pm 3.02$ in the hydro-ethanolic extract of the leaves of Cassia alata ${ }^{27}$. The total phenol contents of four crude extracts determined by Folin-Ciocalteu method were reported as gallic acid equivalents. Phenolics help to prevent cell damage caused by oxidative stress because they exhibit strong antioxidant activities against free radicals (Fig. 1) ${ }^{25}$.

\subsection{Determination of total flavonoid contents}

The result of total flavonoid contents of the extract was $4.32 \pm$ $0.12 \mathrm{mg} / \mathrm{gram}$ of extract. Equation of calibration curve of rutin standard was $y=3.0495 \times-0.0093, R^{2}=0.9833$. The Fig. 2 showed the calibration curve of standard (Rutin). These results are lower than those found by other researchers who revealed that the content of total flavonoids in the methanolic extract of Cassia alata was $24.37 \pm 0.25 \mathrm{mg}$ UK / g dry extract ${ }^{28}$. Flavonoids, for instance, are known to be very potent watersoluble antioxidant.

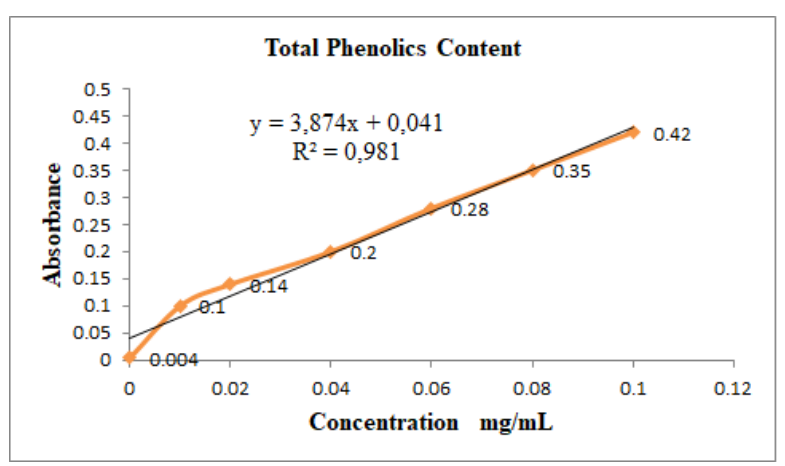

Fig 1: Calibration curve of gallic acid

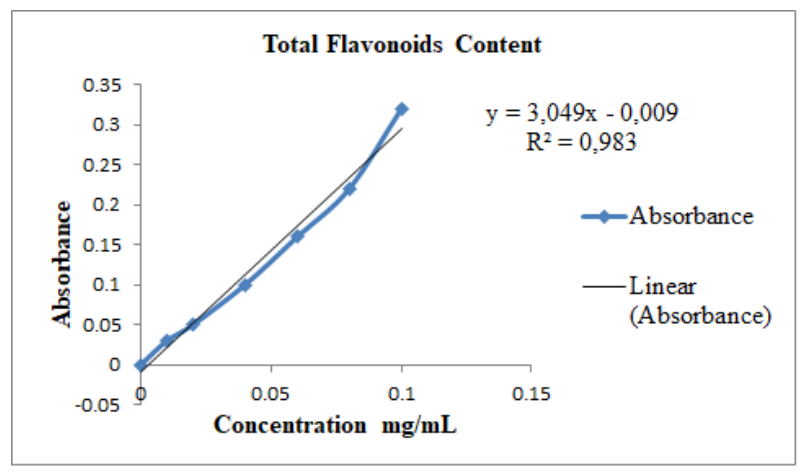

Fig 2: Calibration curve of Rutin

\subsection{DPPH radical scavenging activity}

The principle of DPPH method is based on the reduction of DPPH in the presence of a hydrogen donating antioxidant. Radical DPPH is often used as an indicator to test the ability of the extract to give a hydrogen atom or an electron and therefore antioxidant activity ${ }^{29}$. Extract reduces the color of DPPH due to the power of hydrogen donating ability. DPPH is one of the compounds that possess a proton free radical with a characteristic absorption, which decreases significantly on exposure to proton radical scavengers. Antioxidants may guard against reactive oxygen species (ROS) toxicities by scavenging reactive metabolites and converting them to less reactive molecules. For example, the antioxidant activity of phenols is mainly due to their redox properties, hydrogen donors and singlet oxygen quenchers ${ }^{30}$. DPPH assay is widely used methods for screening antioxidant activity of plant extract. The aqueous extract of $S$. alata were subjected to antioxidant assay against 1,1-diphenyl-2picrylhydrazyl free radical (DPPH) and $I_{50}$ value of $12.79 \mathrm{mg}$. $\mathrm{mL}^{-1}$, was reported. The result of free radical scavenging activity is summarized in Fig 3. A dose-response curve of DPPH radicals scavenging activities was observed that the DPPH radical- 
scavenging activity decreased as the concentration of the extract increased.

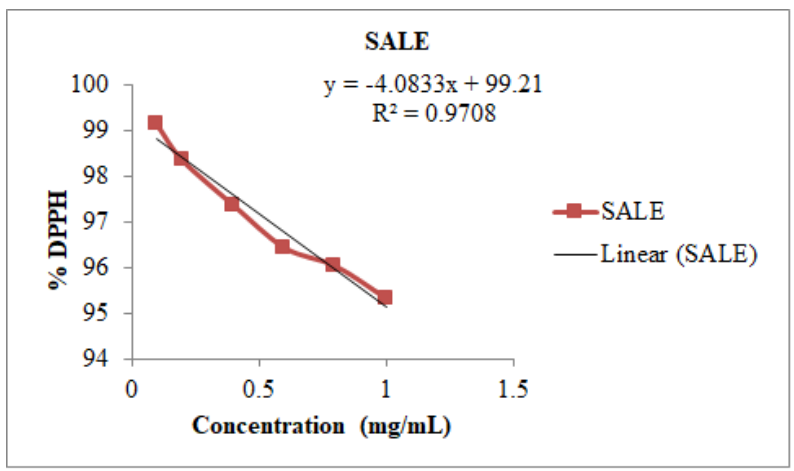

Fig 3: Free Radical Scavenging Activity

\subsection{Ferric-reducing antioxidant power (FRAP) assay}

To better assess the antioxidant effect of aqueous extract of $S$. alata, and alongside its antioxidant power by trapping free radicals, its ability to inhibit lipid peroxidation and its chelation power of iron ions, another aspect was targeted; the reductive power of extract from plants through the FRAP technique. This technique measures the reduction of $\mathrm{Fe}^{3+}$ (iron iron) in $\mathrm{Fe}^{2+}$ (ferrous iron) in the presence of an antioxidant ${ }^{28}$. FRAP assay is the only antioxidants assay that measure antioxidants or reductants in a sample directly and can thus be used to quantify the amounts of total antioxidants or reductants in foods ${ }^{31}$.

The scavenging activity of aqueous extract of $S$. alata toward to ferric-reducing antioxidant decreased from 0.2 to $1.0 \mathrm{mg} / \mathrm{mL}$. It showed the lowest antioxidant activity of $87.82 \%$ at a concentration of $0.1 \mathrm{mg}$. $\mathrm{mL}$ while $\mathrm{IC}_{50}$ value of $2.79 \mathrm{mg} \mathrm{mL}^{-1}$ was reported. This likely indicates that in an extract the bioactive molecules that provide the trapping power of free radicals (DPPH) are themselves responsible for the reducing power of iron. Some authors report that the antioxidant capacity of natural substances may have() a reciprocal correlation with their reducing capacity ${ }^{32}$ and that the latter may, in turn, serve as an important indicator of their antioxidant activity (Fig 4) ${ }^{33}$.

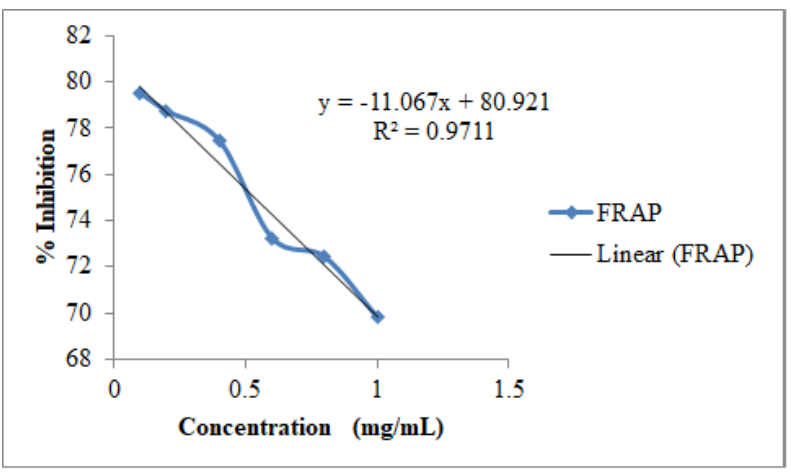

Fig 4: Ferric reducing antioxidant power (FRAP) activity

\section{Conclusions}

The production of free radicals is regulated by our body which has developed antioxidant defenses to protect against the potentially destructive effects of free radicals. The present study however showed that the aqueous extract of $S$. alata is strong antioxidant activity, high total phenolic and total flavonoids content. This extract can be considered as good sources of natural antioxidants for side dishes and medicinal uses. Further in details phytochemical analysis should be done to identify to elucidate the exact bioactive compound which is responsible for the antioxidant action.

\section{Acknowledgements}

Nil

\section{Authors' contributions}

JV designed hypothesis, conceived, wrote the paper, analyzed the data and critically reviewed the manuscript. SDS performed the experiments in this study, assisted with analyzing the data, confirmed the results, and contributed to the writing of the article. All authors reviewed and approved the final manuscript.

\section{Conflicts of interest}

The authors declare that there are no conflicts of interest regarding the publication of this paper

\section{Ethics approval and consent to participate}

This information is not relevant since our study does involve neither animals nor humans.

\section{Consent for publication}

Not applicable since our manuscript does not contain any individual person's data in any form.

\section{References}

1. Rezaeian S, Hamid RP, Javad J. Antioxidant properties of several medicinal plants growing wild in Northeastern Iran. Asian Journal of Plant Science and Research. 2015; 5(2): 63-68.

2. Duthie GG. Lipid peroxidation. European Journal of Clinical Nutrition. 1993; 47: 759-764.

3. Sies H. Oxidative stress: Oxidants and antioxidants. Experimental physiology. 1997; 82 (2): 291-295.

4. Manian R, Anusuya, N, Siddhuraju, P, Manian, S. 2008. The antioxidant activity and free radical scavenging potential of two different solvent extracts of Camellia sinensis

(L.) O.Kuntz, Ficus bengalensis L. and Ficus racemosa L. Food Chemistry, 107: 1000-7.

5. Rates SMK. Plants as source of drugs. Toxicon, 2001; 39(5): 603-613. 
6. Varghese GK, Bose LV, Habtemariam S. Antidiabetic components of Cassia alata leaves: identification through alpha-glucosidase inhibition studies. Pharm Biol. 2013; 51: 345-349.

7. Co LL. Common Medicinal Plants of the Cordillera Region. Bustamante Press, Quezon City, Philippines, 1989.

8. Maramba NP, Saludez JD, Sia IC, Alegre OY, De Asis GA, Bagnaes LB. Guidebook on the Proper Use of Medicinal Plants. Katha Publishing Co., Inc., Quezon City, Philippines; 1993, 86.

9. Guzman-Ladion DH. Healing wonders of herbs. Manila: Philippine Publishing House, 1985.

10. Padua LS, Lugod GC, Pancho JV. Handbook of Philippine Medicinal Plants, UP Los Baños. 1983; 4: 66.

11. Adnaik RS, Bhagwat DA, Raut ID, Mohite SK, Magdum CS. Laxative and Anthelmintic Potential of Cassia alata Flower Extract. Research Journal of Pharmacy and Technology. 2011; 4(1): 98-100.

12. Midawa SM, Ali BD, Mshelia BZ, Johnson J. Cutaneous wound healing activity of the ethanolic extracts of the leaf of $S$. alata $L$ (Caesalpiniaceae). Journal of Medicinal Plants Studies Biological Sciences and Bioconservation. 2010, 2.

13. Palanichamy $S$, Nagarajan $S$, Devasagayama $M$. Effect of Cassia alata leaf extract on hyperglycemic rats. Journal of Ethnopharmacology. 1988; 22(1): 8190.

14. El-Mahmood AM, Doughari JH. Phytochemical screening and antibacterial evaluation of the leaf and root extracts of Cassia alata Linn. African Journal of Pharmacy and Pharmacology. 2008; 2(7): 124-129.

15. Palanichamy S, Nagarajan S. Analgesic activity of Cassia alata leaf extract and kaempferol 3-0sophoroside. Journal of Ethnopharmacology. 1990; 29(1): 73-78.

16. Villasenor IM, Sanchez AC. Cassiaindoline, a new analgesic and anti-inflammatory alkaloid from Cassia alata. zeitschrift für naturforschung C. 2009; 64(5, 6): 335-338.

17. Harborne B. Phytochemical Methods In: A Guide to Modern Techniques of Plant Analysis, $2^{\text {nd }}$ ed. Chapman and Hall, London; 1984, 4-6.

18. Sofowora A. Medicinal Plants and Tradition Medicine in Africa. 3rd ed. Spectrum Books Limited. Ibadan, Nigeria; 2008, 199-204.
19. Trease GE and Evans WC. Pharmacognosy. Harcourt Publishers Ltd., London, 2002; 72p.

20. Singleton VL, Rossi JA. Colorimetry of total phenolics with phosphomolybdic- phosphotungstic acid reagents. Am. J. Enol. Vitic. 1965; 16: 144-158.

21. SingletonV, Orthofer R, Lamuela Raventos RM. Analysis of total phenols and other oxidation substrates and antioxidants by means of FolinCiocalteu reagent. Methods Enzymol. 299; 152-175.

22. Blois MS. Antioxidant determination by the use of a stable free radical. Nature. 1958; 29: 1199-1200.

23. Koleva II, Van BTA, Linssen JPH, De Groot A, Evstatieva LN. Screening of plant extracts for antioxidant activity: a comparative study on three testing methods. Phytochemical Analysis. 2002; 13: 817.

24. Naskar S, Islam A, Mazumder UK, Saha P, Haldar PK, Gupta M. In vitro and in vivo antioxidant potential of hydromethanolic extract of Phoenix dactylifera fruits. J Sci Res. 2010; 2: 144-57.

25. Bougandoura N, Bendimerad N. Evaluation of the antioxidant activity of aqueous and methanolic extracts of Satureja calamintha ssp. Nepeta (L.) Briq. Nature Technologie. 2013; 9.

26. Sujatha J, Asokan S. studies on the antioxidant activity of ethanol extract of cassia alata using FT-IR, HPLC and GC-MS analysis. Int. J. Adv. Res. Biol. Sci. 2017; 4(12): 112-119.

27. Le PTQ. Phytochemical screening and antimicrobial activity of extracts of Cassia alata L. leaves and seeds. Bulgarian Chemical Communications. 2019; 51(3): 378-383.

28. Sarkar B, Khodre S, Patel P, Mandaniya M. HPLC analysis and antioxidant potential of plant extract of Cassia alata. Asian Journal of Pharmaceutical Science \& Technology. 2014; 4(1): 4-7.

29. Loots DT, Van DW, Botes FHL. Aloe ferox leaf gel phytochemical content, antioxidant capacity, and possible health benefits. J. Agric. Food Chem. 2007; 55: 6891-6896.

30. Tepe B, Daferera D, Sokmen A, Sokmen M, Polissiou M. Antimicrobial and antioxidant activities of the essential oil and various extracts of Salvia tomentosa Miller (Lamiaceae). Food Chemistry. 2005; 90: 333340. 
Vedekoi et al., In vitro antioxidant property and phytochemical constituents of Senna alata leaves

31. Blomhoff R, Carlsen M.H, Andersen LF, Jacobs JDR. Health benefits of nuts: potential role of antioxidants. Brit J Nutr. 2006; 96 (suppl. 2): 52-60.

32. Guettaf S, Abidli N, Kariche S, Bellebcir L, Bouriche H. Phytochemical screening and antioxidant activity of aqueous extract of Genista Saharae (Coss. \& Dur.). Der Pharmacia Lettre. 2016; 8 (1): 50-60.

33. Liu J, Jia L, Kan J, Jin $\mathrm{CH}$. In vitro and in vivo antioxidant activity of ethanolic extract of white button mushroom (Agaricus bisporus). Food and Chemical Toxicology. 2013; 51: 310-316. 